\title{
PENGARUH PELARUT METANOL TERHADAP ALUMUNIUM SEBAGAI WADAH OBAT SALEP MATA
}

\author{
Hernowo Widodo ${ }^{1}$, Joni Warta ${ }^{2}$, Maria Ulfah ${ }^{3}$, Amaliah Annisa ${ }^{4}$ \\ ${ }^{1}$ Teknik Kimia, Fakultas Teknik, Universitas Bhayangkara Jakarta Raya, Jl. Perjuangan No. 81, \\ Marga Mulya, Kota Bekasi, 17143 \\ e-mail : hernowo.widodo@dsn.ubharajaya.ac.id
}

\begin{abstract}
Abstrak
Korosi merupakan penurunan kualitas suatu material atau logam akibat reaksi elektrolit pada lingkungannya yang mempengaruhi umur dari material tersebut. Laju korosi adalah kecepatan rambatan atau kecepatan penurunan kualitas suatu bahan terhadap waktu. Proses korosi terjadi pada lingkungan asam, air laut, air hujan, dan tanah merupakan akibat dari reaksi kimia yang juga di akibatkan oleh proses elektrokimia. Tujuan dari penelitian adalah mengetahui ketahanan korosi logam alumunium terhadap variasi pada larutan Methanol $\left(\mathrm{CH}_{3} \mathrm{OH}\right)$. Penelitian ini menggunakan aluminium plat yang akan direndam 5 hari dengan larutan Methanol (CH3OH). Cara pengambilan data dengan melakukan pengujian Scanning Electron Microscopy (SEM) pada setiap spesimen aluminium plat yang telah diberi perlakuan korosi dengan pemanasan pada suhu $60{ }^{\circ} \mathrm{C}$. Larutan Methanol menjadi salah satu faktor penyebab terjadinya korosi pada logam. Jika pada lingkungan bebas, udara, suhu, dan zat asam yang paling banyak ditemukan sebagai faktor penyebab korosi. Laju korosi yang meningkat disebabkan semakin tingginya kadar konsentrasi penyebab korosi tersebut. Pada pembahasan kali ini Methanol sebagai konsentrasi yang digunakan, dan aluminium sebagai logam yang di uji.
\end{abstract}

Kata kunci : SS-304 baja; laju korosi; penghambatan alami

\begin{abstract}
Corrosion is a decrease in the quality of a material or metal due to electrolyte reactions in the environment that affect the life of the material. Corrosion rate is the speed of propagation or speed of decline in the quality of a material with time. Corrosion processes occur in acidic environments, sea water, rain water, and soil are the result of chemical reactions that are also caused by electrochemical processes. The purpose of this study is to determine the corrosion resistance of aluminum metal to variations in the solution of Methanol (CH3OH). This study uses aluminum plates that will be immersed 5 days with a solution of Methanol (CH3OH). How to collect data by testing the Scanning Electron Microscopy (SEM) on each aluminum plate specimen that has been treated with corrosion by heating at a temperature of $60{ }^{\circ}$ C.Methanol solution is one of the factors causing corrosion of metals. If in the free environment, air, temperature, and acidic substances are most commonly found as a factor causing corrosion. The increased corrosion rate is due to the higher concentration of the cause of corrosion. In this discussion Methanol as the concentration used, and aluminum as the metal tested.
\end{abstract}

Keywords : SS-304 steel; corrosion rate; natural inhibitor 


\section{PENDAHULUAN}

Korosi ialah peristiwa perusakan logam yang terjadi karena adanya peristiwa elektrokimia. Elektrokimia merupakan reaksi redoks yang bersangkut paut dengan listrik. Salah satu contoh peristiwa korosi yang sering terjadi pada kehidupan sehari-hari yaitu, karat pada besi. Korosi sudah menjadi kajian yang menarik bagi ilmuwan, dikarenakan keberadaannya dapat dikatakan sebagai musuh besar yang bisa menimbulkan kerugian besar di kehidupan manusia. Institut Battelle pernah menaksir kerugian yang diderita oleh Amerika Serikat akibat korosi yaitu mencapai 70 miliar dolar. Penelitian yang lain yang dilakukan di Inggris, diperkirakan 1 ton baja berubah menjadi karat pada setiap 90 detik (Lestari, 2018). Adapun faktor - faktor yang mempercepat terjadinya korosi yaitu :

1. Air dan kelembaban udara

2. Elektrolit

3. Permukaan logam yang tidak rata

4. Terbentuknya sel elektrokimia

Semakin besar korosi yang terjadi pada suatu bahan, maka semakin besar pula laju korosi yang dihasilkan. Laju korosi adalah kecepatan rambatan atau kecepatan penurunan kualitas suatu bahan terhadap waktu.

Salah satu logam yang dapat terkorosi selain besi adalah aluminium. Aluminium murni $100 \%$ tidak memiliki kandungan unsur apapun selain aluminium itu sendiri, namun aluminium murni yang dijual di pasaran tidak pernah mengandung $100 \%$ aluminium, melainkan selalu ada pengotor yang terkandung di dalamnya. Saat ini aluminium menjadi logam kedua yang sering digunakan setelah besi dalam berbagai industri di dunia (Lestari Indah et all., 2018). Pada era globalisasi saat ini alumunium sudah banyak digunakan dalam kehidupan sehari - hari contohnya yaitu, pembuatan peralatan rumah tangga seperti panci, penggorengan, komponen mesin motor, ornamen pagar dan benda antik. Begitu pula dalam bidang packaging (pengemasan) sudah banyak perusahaan-perusahaan besar yang menggunakan alumunium sebagai wadah pengemasan produk perusahaan tersebut, contohnya yaitu wadah obat salep mata.

Untuk menanggulangi serangan korosi tersebut maka dilakukan penelitian untuk menyelidiki hubungan antara struktur mikro dengan laju korosi, diharapkan nantinya didapatkan suatu metode baru untuk mempertinggi corrosion resistance suatu material dengan memperbaiki bentuk, ukuran, jenis, dan struktur mikronya ( Gunawan , 2017).

\section{METODE PENELITIAN}

Penelitian ini dilakukan untuk mengetahui apa saja peruahan yang terjadi saat perendaman alumunium denngan menggunakan methanol, mengetahui apakah adanya perubahan kehilangan berat setelah dilakukan perendaman dengan menggunakan methanol dan untuk mengetahui apakah terjadi korosi dan mengetahui struktur mikro dari alumunium setelah dilakukan perendaman dengan menggunakan methanol..

Adapun prosedur pengerjaannya yaitu lembaran alumunium yang digunakan sebagai bahan baku pembuatan wadah salep obat mata di potong dan dibentuk dengan ukuran panjang kali lebar $4 \times 4 \mathrm{~cm}$. Alumunium yang telah dibentuk dicuci terlebih dahulu 
kemudian dikeringkan dan ditimbang berat awalnya. Alumunium yang telah dibentuk dibuat menjadi 9 sampel untuk perlakuan panas yang berbeda-beda, yaitu untuk suhu $450^{\circ} \mathrm{C}, 460^{\circ} \mathrm{C}$ dan $470^{\circ} \mathrm{C}$. Tiga sampel dimasukkan kedalam oven pada suhu $450^{\circ} \mathrm{C}$ selama 3 jam dengan waktu tahan (holding time) selama 3 menit. Setelah selesai sampel direndam kedalam metanol selama 5 hari, perlakuan yang sama juga digunakan pada sampel perlakuan panas suhu $460^{\circ} \mathrm{C}$ dan $470^{\circ} \mathrm{C}$. Setelah lima hari barulah sampel dikeluarkan dari proses perendaman dan dilanjutkan dengan pengeringan sampel, kemudian sampel ditimbang berat akhirnya dan diamati perubahan laju korosinya dengan metode kehilangan berat. Kemudian sampel diamati struktur mikronya dengan menggunakan SEM ( SCANNING ELECTRON MICROSCOPY).

\section{HASIL DAN PEMBAHASAN}

Dari hasil perendaman alumunium pada pelarut metanol didapatkan hasil sebagai berikut :

1. Hasil penimbangan berat alumunium selama 5 hari

Tabel 1. hasil penimbangan berat alumunium

\begin{tabular}{|c|c|c|c|c|}
\hline Suhu (c) & Blanko & 60 menit & 120 menit & 180 menit \\
\hline 450 & 0,5375 & 0,5151 & 0,5375 & 0,5624 \\
\hline 460 & 0,563 & 0,5165 & 0,5624 & 0,5623 \\
\hline 470 & 0,5245 & 0,5168 & 0,5242 & 0,5375 \\
\hline
\end{tabular}

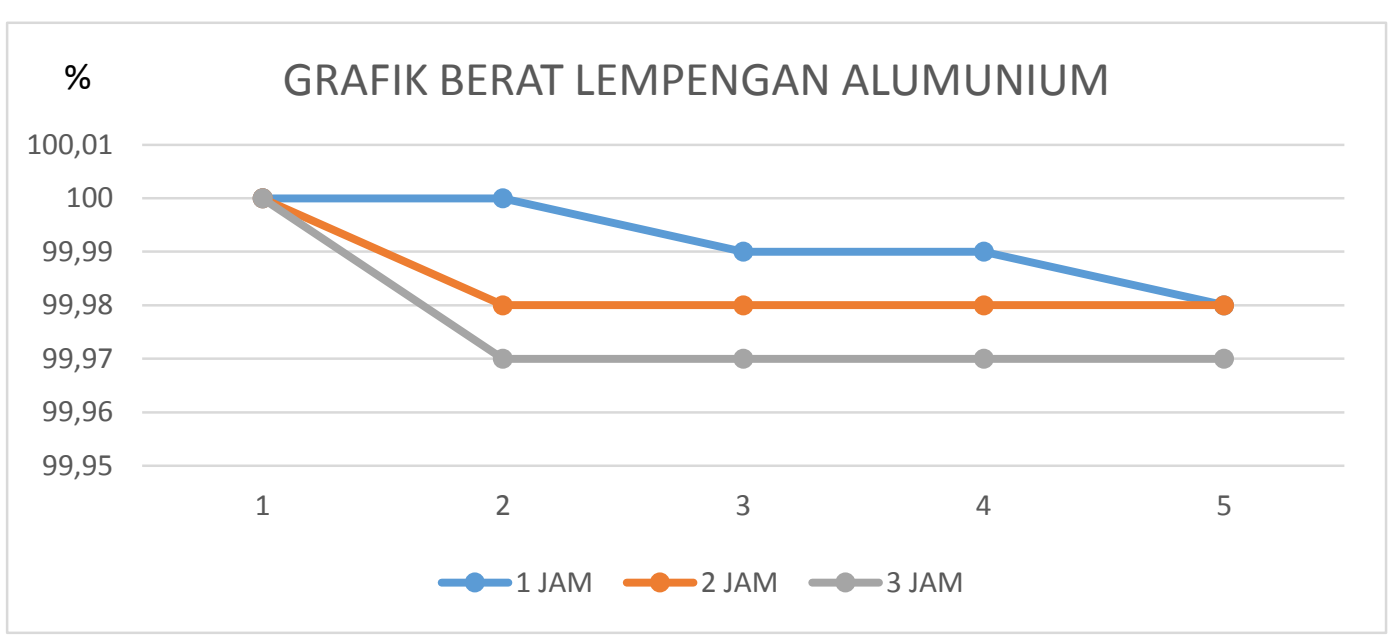

Gambar 1. grafik berat alumunium

Dari hasil penimbangan alumunium setelah direndam dengan menggunakan pelarut metanol didapatkan berat yang stabil yang artinya bobot alumunium tersebut tidak mengalami penurunan atau kehilangan bobot, serta dapat dilihat dari hasil grafik gambar 1 . 
2. Hasil Uji Scanning Electron Microscopy (SEM)

a. Blanko

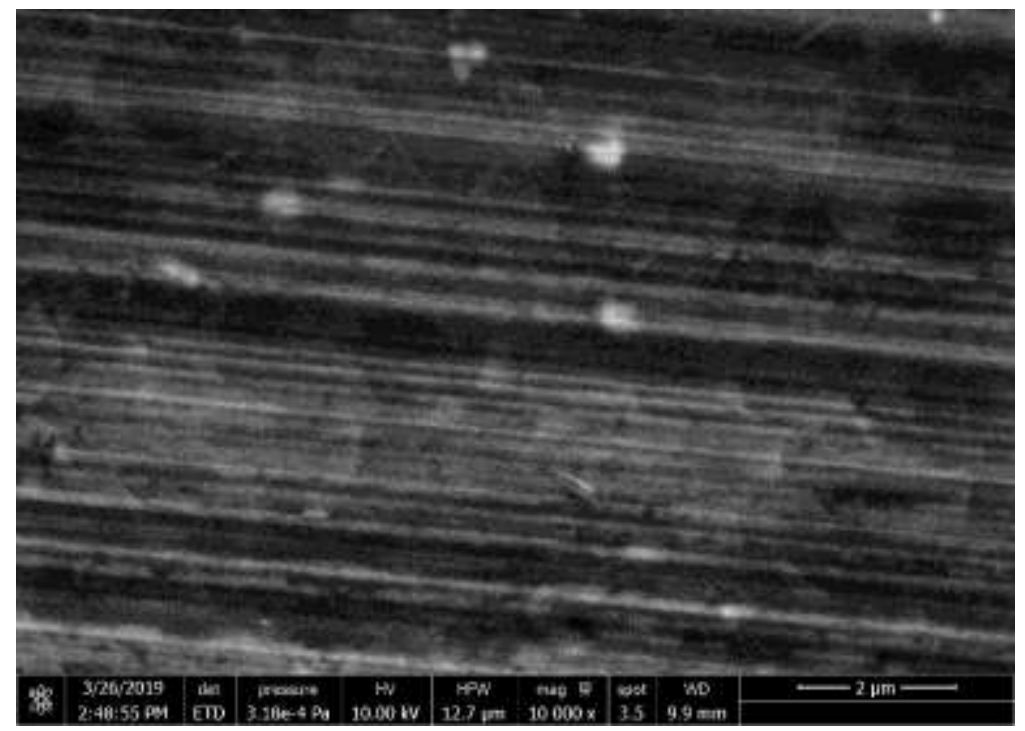

Gambar 2. Hasil Uji SEM Blanko untuk pembesaran 10000x

b. Pengujian $450^{\circ} \mathrm{C}$

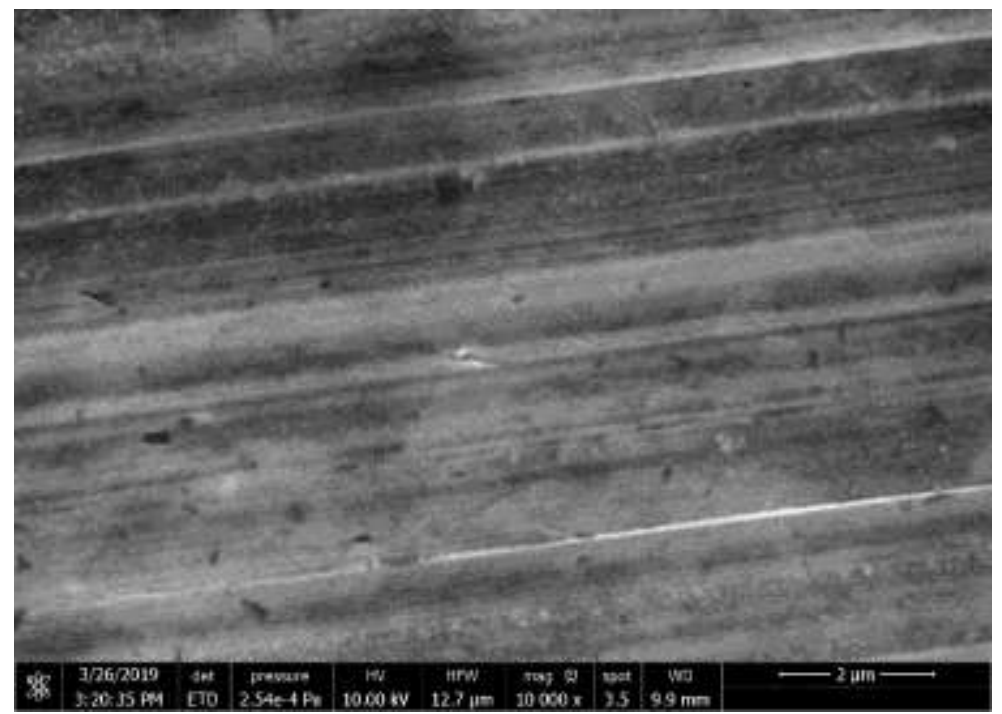

Gambar 3. Hasil Uji SEM Alumunium pemanasan $450^{\circ} \mathrm{C}$ 
c. Pengujian $460^{\circ} \mathrm{C}$

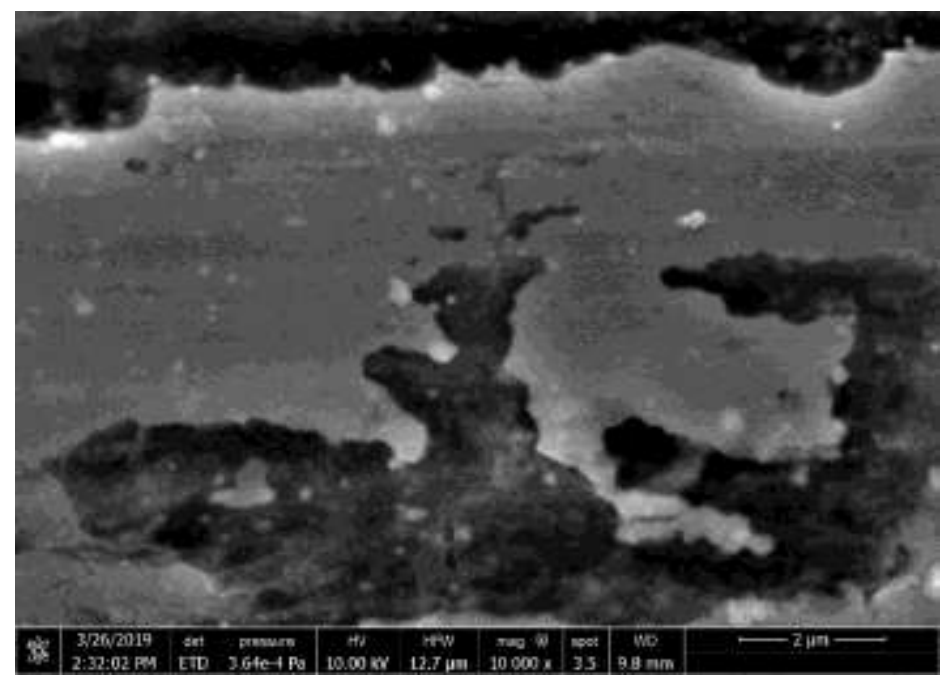

Gambar 4. Hasil Uji SEM Alumunium pemanasan $460^{\circ} \mathrm{C}$

d. Pengujian $470^{\circ} \mathrm{C}$

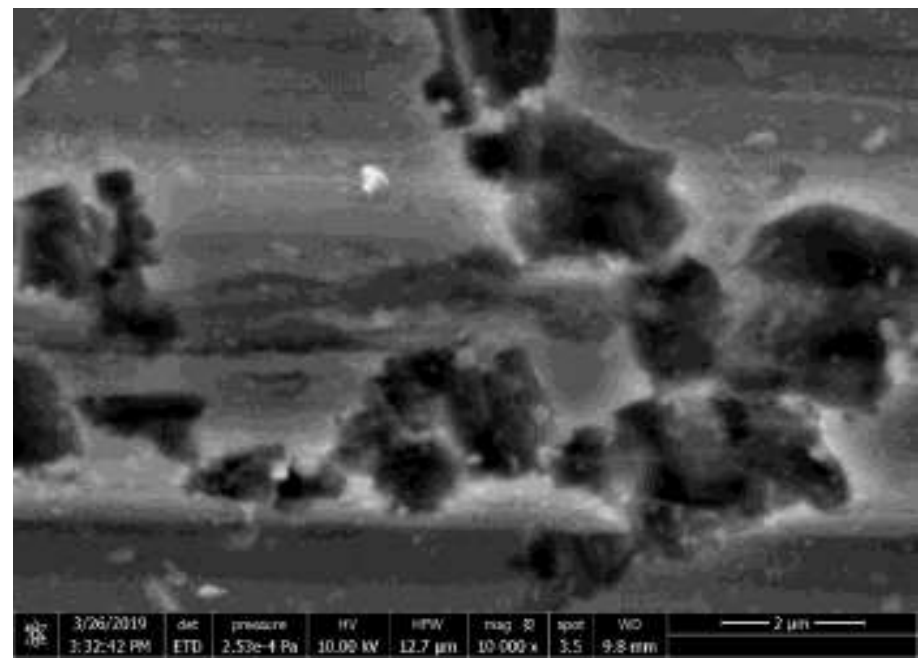

Gambar 5. Hasil Uji SEM Alumunium pemanasan $470^{\circ} \mathrm{C}$

Dari hasil yang didapat, dapat disimpulkan bahwa alumunium yang direndam dengan menggunakan pelarut metanol tidak mengalami penurunan bobot dan selalu dalam kondisi stabil, serta tidak mengalami korosi . Pelarut metanol aman dipakai untuk campuran salep mata dengan wadah alumunium.

Dari hasil uji SEM diperoleh gambaran secara mikroskopik seperti pada blanko lebih rapat dan di suhu $470^{\circ} \mathrm{C}$ memiliki sruktur mikroskopis yang rengang. 


\section{KESIMPULAN}

Dari hasil penelitian studi pengaruh pelarut metanol terhadap alumunium sebagai wadah obat salep mata dapat disimpulkan sebagai berikut :

1. Pelarut metanol tidak mempengaruhi perubahan yang signifikan pada alumunium, mulai dari berat maupun strukturnya

2. Pelarut metanol tidak dapat menyebabkan korosi pada aluminum pada waktu perendaman selama 5 hari

3. Alumunium adalah wadah yang baik digunakan sebagai obat salep mata, karena sifatnya yang tidak mudah terkorosi

4. Pengaruh pemanasan pada suhu $470^{\circ} \mathrm{C}$ menyebabkan alumunium mengalami perubahan struktur yang signifikan

\section{DAFTAR PUSTAKA}

[1] Bandriana, Bernardus; Nyoman Udhi; dan Bagus Jihad., 2004, Ketahanan Korosi Baja Anti Karat Pada Operasi Suhu Tinggi, 2-3.

[2] Gita Anggaretno., Imam Rochani., Heri Supomo. 2012. Korosi pada Pengelasan Pipa API 5L Grade X65 dengan Media Korosi FeCl3. Jurnal Teknik ITS, Vol. 1, No. 1, ISSN: 2301-9271.

[3] Hariyono, Heri. 1999. Pengaruh Lingkungan Terhadap Efisiensi Inhibisi Asam Askorbat (Vitamin C) pada Laju Korosi Tembaga, Universitas Kristen Petra, 100$107 \mathrm{~S}$.

[4] J.R. Davis. (1999). Corrosion of Aluminum and Aluminum Alloys (\#06787G). ASMS specialty Handbook International.

[5] MT, Mulyati. 2014, Bahan Ajar Mekanika Bahan, 1-6

[6] Prasetya, E.H; Ranto; dan Suharno, Pengaruh Konsentrasi Inhibitor Asam Askorbat dan Konsentrasi Larutan Natrium Klorida Terhadap Laju Korosi Baja Karbon Rendah Pasca Pelapisan Cat Epoxy, 1-11S.

[7] Suratman. Rochim. 2013. Karakteristik Korosi Aluminium dan Baja Tahan Karat, $1-12 S$.

[8] Surdia, Tata, dan Saito, S. 1985. Pengetahuan Bahan Teknik. Jakarta: Pradnya Paramitha. 